\title{
European Commission questions commercial blood bank benefit
}

Citing ethical concerns, an advisory body of the European Commission (EC) has recommended against private, for-profit banks of umbilical cord blood as a source of hematopoietic stem cells.

In a report released in March, the European Group on Ethics in Science and New Technologies (EGE) questioned the legitimacy of commercial cord blood banks for autologous use "as they sell a service which has presently no real use." The report, commissioned in 2001 by EC president Romano Prodi, says the banks "promise more than they can deliver."

There are about 100 cord blood banks worldwide, $40 \%$ of them in Europe. About $75 \%$ are public, non profit banks, but recent years have seen the emergence of commercial banks, which offer to conserve cord blood for up to 15 years for one's own use or for use in close relatives.

In contrast, public banks store cord blood cells for allogeneic transplants in unrelated recipients. The probability of needing an autologous transplant is about 1 in 20,000 during the first 20 years of life, the EGE notes. Moreover, the possibility of using stem cells from one's own cord blood is "currently purely hypothetical" and research in the field is at an early stage, the report adds.

In exceptional cases where autologous use may be justified-for families at risk of specific diseases, for instance- - the EGE recommends storing cord blood in public banks.
Although they are not used widely, cord blood cells have some advantages compared with bone marrow. Collecting the cells is relatively easy and noninvasive. Because the cells are less likely to induce immunological reactions, the subtype for allogeneic transplants does not need to be a perfect match.

Cord blood is also a source of high-quality stem cells for research, notes Jordi Petriz, a researcher at the Barcelona-based IDIBAPS institute. For instance, stem cells from umbilical cord blood are more naive than any other hematopoietic stem cell, Petriz says. Because commercially available cord cells are expensive, he adds, more commercial firms might increase competition and decrease prices.

Xavier Bosch, Barcelona

\section{Debate escalates on source of sub-Saharan Africa's AIDS epidemic}

Sub-Saharan Africa is home to two-thirds of the world's 40 million HIV/AIDS cases. But experts are still debating whether unsafe injections or unprotected sex is the culprit behind the region's skyrocketing statistics.

Some studies estimate that up to $40 \%$ of transmissions in the region are attributable to unsafe injections, but the World Health Organization (WHO) recently published a scathing critique of that theory (Lancet 363, 482-488; 2004). Pennsylvania-based consultant David Gisselquist and his colleagues first published estimates that up to half of the injections administered in sub-Saharan Africa are given with reused equipment (Int. J. STD AIDS 13, 152-159; 2002).

Based on multiple studies, Gisselquist's team concluded that "general population studies through 1988 suggest that medical exposures were responsible for more African HIV than sexual exposures."

The WHO acknowledges that unsafe injections and other substandard health-care practices have become a significant problem in many parts of the world. But the organization maintains that dirty needles are responsible for only $2.5 \%$ of HIV transmissions in Africa. George Schmid, a WHO medical officer and lead author of the Lancet critique, admits that such a wide discrepancy in estimates leaves the door open for debate.

"It's obvious [with differences of] a magnitude of 10 to think, 'could one side be that wrong?" Schmid says. "To be honest, there's basically no conclusive evidence on the issue."

To some researchers, the entire discussion seems superfluous. "[The debate] is rubbish," says Elly Katabira, associate dean of research at Kampala's Makerere University Medical School. "Cleaning needles is standard practice, even without AIDS. We've been sterilizing needles for 30 years." To assume that the developing world fails to grasp a simple concept like needle sterilization, he says, smacks of racism.

Ironically, Gisselquist reaches a similar conclusion about the WHO's stance. "It's a racist idea, and a manipulative one, that you've got to tell Africans that they've got to be careful about their sexual behaviors and not worry about their health care," he says. "It's a racist proposal to be saying that they can't handle information about both risks."

Gisselquist's ideas have captured the attention of the US Congress, which in January earmarked up to $\$ 75$ million as part of its Global AIDS Initiative toward "safe and appropriate" injections.

That is a reasonable sum to reduce patients' risk, Schmid says. Still, he adds, scientists should investigate other potential pitfalls, such as contamination of breast milk, administration of circumcisions and continued reliance on informal community surgical procedures. "If the part of the health-care system that's unsafe is not unsafe injections, then you've really spent the money in the wrong way," he says.

But tracing the transmission source of an HIV-infected patient can be tricky—as seen in a recent study of 14 HIV-positive South African children whose infections were attributed to "inexplicable causes" (S. Afr. Med. J. 94, 188-193; 2004).

Each of the children's mothers was HIV negative, says lead investigator Mark Cotton of the University of Stellenbosch. In at least two cases, the children initially tested negative and were discovered to be positive only after health-care workers reported needle-stick injuries.

Researchers found that 12 of the 14 children were given intravenous lines. It is possible that overburdened health-care workers shortchanged sterilization procedures and flushed the lines with HIV-contaminated saline, Cotton says. But that's just one hypothesis-other explanations for the infections include unidentified sexual abuse and hospital-contaminated breast milk.

Cotton admits that evidence of hospitalacquired HIV among the children is inconclusive, but fears there could be many more cases.

To identify suspect health-care practices, the Human Sciences Research Council of South Africa is launching an extensive case-control study in Botswana, Zimbabwe and South Africa's northwestern provinces. The project will also evaluate hospitals' infection-control practices and test 'sterilized' medical and dental instruments for the presence of residual viral contamination, says Olive Shisana, the council's executive director.

"In the event we do find there are things that have to be corrected, the action has to be very swift," says Shisana. "Science should be the way that guides policy, on the basis of data."

Bruce Diamond, New York 